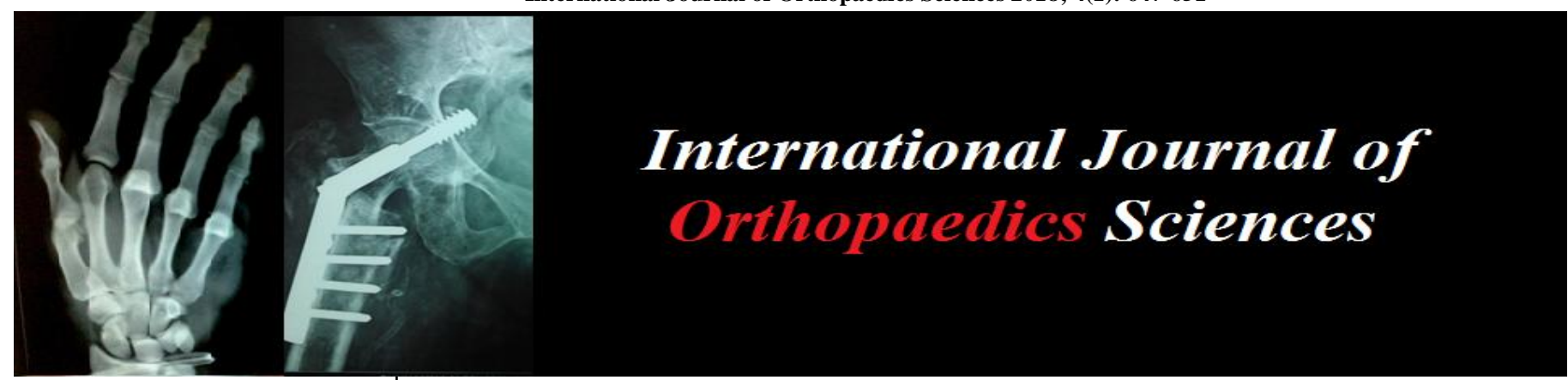

ISSN: $2395-1958$

IJOS 2018; 4(1): 647-651

(C) 2018 IJOS

www.orthopaper.com

Received: 12-11-2017

Accepted: 13-12-2017

Dr. Lakshman Prasath Govindarajan

Asst. Professor, Department of

Orthopaedics, Annapoorna

Medical College and Hospital,

Salem, Tamil Nadu, India

Dr. Arun Rajamanickam

Senior Resident, Department of Orthopaedics, Vinayaka Missions

KirupanandaVariyar Medical

College and Hospital, Salem,

Tamil Nadu, India

Shankar Radha Krishnan

Vinayaka Missions

KirupanandaVariyar Medical

College and Hospital, Salem,

Tamil Nadu, India

\section{Comparison between cemented and un-cemented hemiarthroplasty among the patients with fracture neck of femur}

\author{
Dr. Lakshman Prasath Govindarajan, Dr. Arun Rajamanickam and \\ Shankar Radha Krishnan
}

DOI: https://doi.org/10.22271/ortho.2018.v4.i1j.92

\section{Abstract}

Background: Hemiarthroplasty has been accepted as the treatment of choice for displaced femoral neck fractures. In the recent years the use of bone cement in hemiarthroplasty had become a controversial topic as few studies had recommended the use of uncemented hemiarthroplasty because of its minimal complications.

Aim: To compare and assess the efficacy of cemented and uncemented bipolar hemiarthroplasty prosthesis among patients with femoral neck fractures.

Methodology: A prospective comparative study was conducted at our hospital from the department of Orthopaedics for a period of one year. Patients aged more than 18 years of age of any gender with fracture neck of femur were included as study subjects. A total of 60 patients were included as our study subjects. It was divided into two groups of 30 each, one group received the cemented and the other group underwent an uncemented hemiarthroplasty. Patients were followed up on the $6^{\text {th }}$ postoperative week for radiological assessment of the implant position and further advised for complete weight bearing as tolerated. Subsequently patients were followed up at $3^{\text {rd }}$ and $12^{\text {th }}$ month. At each visit patient was assessed for recovery based on harris hip score which includes post operative pain, return to activities of daily living, shortening of limb, range of movements, deformity and gait.

Results: The duration of surgery was found to be longer in the cemented group with a mean duration of 82.8 mins and among the un-cemented group it was 63.6 mins. The intra-operative blood loss in $60 \%$ of the patients among the cemented group had more than $300 \mathrm{ml}$ whereas among the un-cemented group it was only $13.3 \%$ had more than $300 \mathrm{ml}$ of blood loss. The mean Harris hip score at the end of 12 months among the cemented group was 81.6 and among the un-cemented group it was 79.07 and both the groups showed a statistical significant improvement in their scores when compared to the score at 3 months whereas no significant difference observed in the scores between the two groups.

Conclusion: Both the cemented and uncemented hemiarthroplasty are equally good options in the treatment of fracture neck of femur among elderly patients with minimal complications among the two methods. More data comparing uncemented and cemented hemiarthroplasty in patients with femoral neck fracture are still needed to substantiate our findings.

Keywords: Fracture neck of femur, cemented hemiarthroplasty, uncemented hemiarthroplasty, harris hip score

\section{Introduction}

India being a country with more than $10 \%$ of geriatric population and among the various morbidities in them, fracture neck of femur is one of the major public health problem.

The lifetime risk of these fractures is $9 \%$ in a female of 50 years age but rises to $12 \%$ at 70 years and $18 \%$ by 90 years ${ }^{[1]}$. The limited and unprotected blood supply to the femoral head, the intra capsular location of these fractures and osteoporosis are the major factors that inhibit healing leading to avascular necrosis of femoral head ${ }^{[2]}$. Surgery being the first choice of treatment for femoral neck fractures, internal fixation which was initially introduced had a high failure rate resulting in complications like nonunion and avascular necrosis ${ }^{[3]}$. These complications were addressed with the advent of hemiarthroplasty surgery for fracture neck of femur. Although some authors have reported better results with internal fixation, still hemiarthroplasty had been accepted as the treatment of choice for displaced femoral neck

\section{Dr. Arun Rajamanickam}

Senior Resident, Department of Orthopaedics, Vinayaka Missions KirupanandaVariyar Medical College and Hospital, Salem,

Tamil Nadu, India 
fractures. Total hip arthroplasty is an alternative for active patients with a long life expectancy and arthritic joints ${ }^{[4]}$. In the recent years the use of bone cement in hemiarthroplasty had become a controversial topic as few studies had recommended the use of uncemented hemiarthroplasty because of its minimal complications.

Cementing has potential physiologically adverse side effects. The major side effects cardiac arrhythmias and cardiorespiratory collapse, which occasionally occur upon in cementing are potentially fatal complications are caused either by embolism from marrow contents forced into the circulation or by a direct toxic effect of the cement ${ }^{[5]}$. A study done by Clark et al had found a transient but significant reduction in cardiac output and stroke volume for those receiving cement ${ }^{[6]}$.

There is some evidence of inferior short-term results, with decreased mobility and more pain when using an uncemented implant, and concerns regarding fixation problems with uncemented stems in osteoporotic bone have been raised. This may be the result of the inferior method of fixation or the design of the prosthesis ${ }^{[7,8]}$.

The recent introduction of modular hemiarthroplasty for hip fractures had led to a number of prospective trials comparing cemented and uncemented hemiarthroplasty and had shown a very similar results for both the procedures. However a recent registry based study comparing (mostly modular) cemented and uncemented hemiarthroplasty, more reoperations were detected in patients treated with uncemented hemiarthroplasty [9-11]. These studies, though they had compared many variables of the two techniques using meta-analysis still it needs to be improved in certain aspects. Firstly, predictable bias from quasi-RCTs or non-RCTs exists in all the above mentioned studies. Secondly, complications of cemented and uncemented hemiarthroplasty have not been stratified before comparison and lastly the study which was published in 2012 have not been enrolled in any meta-analysis ${ }^{[12]}$. In India as of today very few studies were conducted in comparing the cemented and uncemented hemiarthroplasty and so this study was undertaken to assess the efficacy between these two techniques.

\section{Aim}

To compare and assess the efficacy of cemented and uncemented bipolar hemiarthroplasty prosthesis among patients with femoral neck fractures.

\section{Methodology}

A prospective comparative study was conducted at our hospital from the department of Orthopaedics for a period of one year. The study was started after getting the clearance from the institutional ethical committee. Patients aged more than 18 years of age of any gender with fracture neck of femur were included as study subjects. Patients with very severe trauma associated with head injuries, patients with preexisting sepsis and those who were bedridden before injury for any other causes were excluded from the study. A total of 60 patients were reported in the above mentioned study period satisfying our inclusion and exclusion criteria. It was divided into two groups of 30 each, one group received the cemented and the other group underwent an uncemented hemiarthroplasty. Informed consent from all the patients involved in the study. Complete medical evaluation was carried out to rule out any underlying medical illness and the pre anesthetic evaluation was done by the anesthesiologist. Patient is then subjected to surgery under appropriate anesthesia. Patients underwent a bipolar hemiarthoplasty with either a cemented or an uncemented prosthesis. The arthoplasties were performed through a posterior approach with the patient in a lateral decubitus position using spinal anaesthesia. Using box osteotome, femoral canal was prepared, taking care to lateralize the implant. Femoral canal is broached serially and the most snuggly fitting femoral stem was taken as the femoral stem size. Depending upon appropriate size modular bipolar implant was placed. In the cases of cemented hemiarthroplasty, appropriate quantity of cement after preparation was placed into the canal before placing the femoral stem. The polymethyl-metacrylate cement was used as cemented stem among the cemented arthroplasty group. Post-operatively all the vital parameters were monitored adequate blood transfusion was made for the needed patients along with antibiotic and DVT prophylaxis. Pain management was done by injectable NSAID's.

Static quadriceps exercises were started and patients were made to sit up on bed on first post operative day. Gait training exercises was started on the 3 rd post-operative day. Patients were discharged after suture removal on the $12^{\text {th }}$ postoperative day. Patients were followed up on the $6^{\text {th }}$ postoperative week for radiological assessment of the implant position and further advised for complete weight bearing as tolerated. Subsequently patients were followed up at $3^{\text {rd }}$ and $12^{\text {th }}$ month. At each visit patient was assessed for recovery based on harris hip score which includes post operative pain, return to activities of daily living, shortening of limb, range of movements, deformity and gait. Radiological assessment was done for assessing the signs of loosening, migration, wear and implant failure.

All the data were entered and analysed using SPSS version 21. Mean and standard deviation was derived for all the parametric variables. Chi-square was used to assess the association between the qualitative variables. The mean scores of both the groups were compared and analysed using $\mathrm{T}$ test for deriving statistical inference.

\section{Results}

Table 1 shows the age and sex wise distribution of the study subjects among the cemented and un-cemented group. It is seen from the table that the majority of the study subjects are in the age group between 70 and 80 years and the distribution of age and gender was almost similar in both the groups, whereas the females were more than males in both the groups and the difference was found to be statistically significant. The mean age was 72.6 in cemented group and it was 73.8 in un-cemented group. All our patients in both the groups sustained the injury following a trivial trauma. Only two patients in the cemented group and one patient in the uncemented group had the hemoglobin levels of less than $9 \mathrm{gms} \%$ and the prevalence of diabetes was $22 \%$ in cemented group and $26 \%$ in un-cemented group. The average time interval between the incident of injury and surgery was around 6 to 7 days in both the groups and the maximum interval was 14 days (table 2). The duration of surgery was found to be longer in the cemented group with a mean duration of 82.8 mins and among the un-cemented group it was 63.6 mins and among the un-cemented group $36 \%$ of the subjects underwent the surgery in less than 60 mins, whereas among the cemented group more than $70 \%$ had the duration of more than 80 mins and the difference in duration of surgery between the two groups was found to be statistically significant (table 3). 
The intra-operative blood loss in $60 \%$ of the patients among the cemented group had more than $300 \mathrm{ml}$ and $6.6 \%$ of them had more than $500 \mathrm{ml}$ compared to the un-cemented group where it was only $13.3 \%$ had more than $300 \mathrm{ml}$ of blood loss and the remaining patients had a blood loss of between $150-$ $300 \mathrm{ml}$ and the difference was found to be statistically significant (table 4). The functional outcome of the patients who had undergone hemiarthroplasty were measured in terms of pain, limp, use of cane and the range of movements at the end of 12 months. It was found that at the end of 12 months $83 \%$ of the subjects in cemented group had nil pain compared to only $63 \%$ in the un-cemented group and the difference was found to be statistically significant. A mild limp gait was observed in equal numbers at the end of 12 months in both the groups. Majority of the subjects in the un-cemented group had used cane for long walks $(73.3 \%)$ compared to only $53 \%$ in the cemented group and the difference was found to be statistically significant. Among the different range of movements like flexion, abduction and rotation we did not find a statistically significant difference between the cemented and un-cemented group (table 5). The Harris hip score comparison between the cemented and un-cemented group at the end of $3^{\text {rd }}$ and $12^{\text {th }}$ month was shown in table 6 . It is inferred from the table that at the end of 3 months majority of the subjects in both the groups had a fair score in the range of $70-79$ and similarly at the end of 12 months most of the subjects in both the groups had a good score (80-89) and a statistical significant improvement was seen at the end of 12 months compared to 3 months in both the groups, whereas comparing the scores between cemented and un-cemented group we did not a find a statistically significant difference both at the end of $3^{\text {rd }}$ month and the $12^{\text {th }}$ month.

\section{Discussion}

Bipolar hemiarthoplasty is the most opted surgical treatment modality for displaced fracture neck of femur among the elderly population. The immediate functional recovery and the reduced rate of reoperation when compared to internal fixations had made the surgeons to opt for hemiarthroplasty. However the results of all hemiarthroplasties are not the same which could be probably due to the different variety of prosthesis that is being used, the surgical approach chosen and the post operative rehabilitation which were practiced. Whether a bipolar prosthesis used in an uncemented hemiarthoplasty could yield the same clinical results as in cemented hemiarthoplasty for treatment of treatment of fracture neck of femur is unclear and so this study was undertaken to study the functional outcome between cemented and un-cemented hemiarthroplasty among the patients with fracture neck of femur.

Our series of patients in both the groups is in no exception to the fact that the fractures of the neck of femur are more common in elderly population as the mean age of our study subjects was more than 70 years and the global epidemiology also admit this fact. Khan et al. ${ }^{[7]}$ and Santini et al. ${ }^{[13]}$ also noted the same scenario among our Indian subjects. Female preponderance in our study is mainly due to the fact that osteoporosis is one of the main risk factor for fracture neck of femur, which is more common in females. As mentioned in numerous studies on proximal femoral fractures, regarding mechanism of injury, trivial fall [like tripping on the road, walking on uneven grounds] has been the main causative factor ${ }^{14-16]}$. The same is true in our series also. In our study all patients sustained fracture following simple/trivial fall. However in our observation more than the mechanism of injury it is the bone quality that has prime impact on fracture pattern. More than $60 \%$ of the patients had presented to the hospital as early as within 7 days of injury. Only about $10 \%$ of patients had presented in more than10 days following the injury. We did not have any neglected fractures in our study. This delay in presentation since injury did not have any significant bearing. This fact has also been stressed in various literatures that acceptable time delay in presentation since injury is yet to be established ${ }^{[17,18]}$.

The duration of the surgical procedure for cemented hemiarthoplasty was significantly higher than the uncemented hemiarthroplasty and the studies done by Santini S et al. ${ }^{[13]}$ and Wender Figved et al. ${ }^{[9]}$ had also noticed this increase in the duration of surgery in cases of cemented hemiarthoplasties but however this increased duration of surgical time did not alter or affect the total functional recovery of the patient. In our study we noted a significant increase in intra-op blood loss in case of cemented hemiarthoplasties as compared to uncemented ones. Wender Figved et al reported duration of 70.2 min with a blood loss of $300 \mathrm{ml}$ in uncemented group and $82.6 \mathrm{~min}$ with a blood loss of $390 \mathrm{ml}$ in the cemented group ${ }^{[9]}$. Jaimo Ahn, Li-Xing Man et al, in their study recorded two operative parameters of blood loss and surgical times were lower for the uncemented cohorts ${ }^{[19]}$. Another study done by Ankush V Mohabey et al reported that among uncemented group the mean duration of surgery was 78.25 min with a mean amount of blood loss of $176 \mathrm{ml}$, where as in the cemented group the mean duration of surgery was $111.5 \mathrm{~min}$ and mean amount of blood loss being $310.50 \mathrm{ml}$ and the difference was found to be statistically significant ${ }^{[20]}$.

In our study we found a statistical significant difference in the pain scoring $(p<.05)$ between the cemented and uncemented groups with cemented group patients showing lesser pain score, which matches with the other similar studies like M. J. Parker et al concluded that degree of residual pain was less in those treated with a cemented prosthesis $(p<0.0001)$ three months after surgery ${ }^{[21]}$. R.J. Khan et al, by prospective assessment revealed a highly statistically significant greater deterioration in pain $(\mathrm{P}=0.003)$, walking ability $(\mathrm{P}=0.002)$, use of walking aids $(\mathrm{P}=0.004)$ and activities of daily living $(\mathrm{P}=0.009)$ in the uncemented group ${ }^{[7]}$. Few studies done by Jaimo Ahn, Li-Xing Man et al. ${ }^{[19]}$ noted that persistence of pain did not reach statistical significance between groups and Wender Figved et al. ${ }^{[9]}$ reported there were no differences in pain scores and use of analgesics and a study done by Hansen et al did not find any statistically significant difference in pain score between the groups ${ }^{[22]}$. The results in our study did not show any statistical difference in the evaluation of limp which matches with other similar studies like Jaimo Ahn, Li-Xing

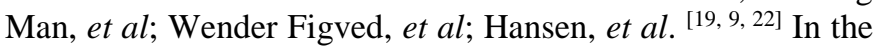
present study we found that the use of walking aids was more common among the un-cemented group than that of the cemented group and the difference was found to be statistically significant and the results are in par with the study done by R J Khan et al. ${ }^{[7]}$

The mean Harris hip score among the un-cemented group and cemeneted group at the end of 12 months in the present study was 79 and 81 respectively and no statistical significant difference was seen between these scores and it is almost similar to the results quoted by Ankush $\mathrm{V}$ Mohabey et al where the score was 85 and 81 among the un-cemented and cemented group ${ }^{[20]}$. A study done by Deangelis JP et al. ${ }^{[10]}$ found that in the treatment of nonpathologic displaced femoral neck fractures, the use of cemented and uncemented 
femoral components is associated with similar functional outcome at 6 months and similarly study done by M. J. Parker et al. ${ }^{[21]}$ noted no statistically significant difference between the cemented and the uncemented groups with regard to mortality, implant-related complications, re-operations or post-operative medical complications. We did not notice any major complications like cardio pulmonary embolism, in cases of cemented hemiarthoplasty, as described in most of the literatures and also complications related to un-cemented hemiarthroplasty like persistent thigh pain, subsidence of prosthesis \& stress shielding has not been reported in the present study which is probably because of the standard press fit bipolar femoral stems and these finding correlates with the randomized controlled trial done by Wender Figved et al. ${ }^{[9]}$

Table 1: Age and gender wise distribution of the study subjects

\begin{tabular}{|c|c|c|c|c|c|c|}
\hline \multirow{2}{*}{ Age group } & \multicolumn{2}{|c|}{ Cemented group $(n=30)$} & \multirow{2}{*}{$P$ value } & \multicolumn{2}{|c|}{ Un-cemented group $(n=30)$} & \multirow[t]{2}{*}{ P value } \\
\hline & Male & Female & & Male & Female & \\
\hline $50-60$ & 0 & $1(4.3 \%)$ & \multirow{5}{*}{0.003} & 0 & $2(7.6 \%)$ & \multirow{5}{*}{0.0028} \\
\hline $61-70$ & $3(42.8 \%)$ & $5(21.7 \%)$ & & $1(25 \%)$ & $5(19.2 \%)$ & \\
\hline $71-80$ & $2(28.5 \%)$ & $8(34.7 \%)$ & & $2(50 \%)$ & $9(34.6 \%)$ & \\
\hline$>80$ & $2(28.5 \%)$ & $9(39.1 \%)$ & & $1(25 \%)$ & $10(38.4 \%)$ & \\
\hline Total & $7(100 \%)$ & $23(100 \%)$ & & $4(100 \%)$ & $26(100 \%)$ & \\
\hline
\end{tabular}

Table 2: Distribution of the study subjects based on the time between injury and surgery

\begin{tabular}{|c|c|c|c|}
\hline Time between injury and surgery (in days) & Cemented group $(\mathbf{n}=\mathbf{3 0})$ & Un-cemented group $(\mathbf{n}=\mathbf{3 0})$ & P value \\
\hline $1-3$ & $8(26.6 \%)$ & $9(30 \%)$ & $10(33.3 \%)$ \\
\hline $4-7$ & $12(40 \%)$ & $8(26.6 \%)$ & 0.739 \\
\hline $8-10$ & $6(20 \%)$ & $3(10 \%)$ & $7.1 \pm 3.2$ \\
\hline Mean \pm SD & $4(13.3 \%)$ & $6.8 \pm 3.8$ & \\
\hline
\end{tabular}

Table 3: Distribution of the study subjects based on the duration of surgery

\begin{tabular}{|c|c|c|c|}
\hline Duration of surgery & Cemented group $(\mathbf{n}=\mathbf{3 0})$ & Un-cemented group $(\mathbf{n}=\mathbf{3 0})$ & P value \\
\hline Upto $60 \mathrm{mins}$ & 0 & $11(36.6 \%)$ & \\
\hline $61-70 \mathrm{mins}$ & 0 & $19(63.3 \%)$ & $<$ \\
\hline $71-80 \mathrm{mins}$ & $8(26.6 \%)$ & 0 & 0.0001 \\
\hline$>80 \mathrm{mins}$ & $22(73.3 \%)$ & $63.6 \pm 4.8$ \\
\hline
\end{tabular}

Table 4: Distribution of the study subjects based on the intra-operative blood loss

\begin{tabular}{|c|c|c|c|}
\hline Intra-operative blood loss & Cemented group & Un-cemented group & P value \\
\hline $100-300 \mathrm{ml}$ & $10(33.3 \%)$ & $26(86.6 \%)$ & \multirow{2}{*}{$\mathbf{0 . 0 0 0 3}$} \\
\hline $300-500 \mathrm{ml}$ & $18(60 \%)$ & $4(13.3 \%)$ & \\
\hline$>500 \mathrm{ml}$ & $2(6.6 \%)$ & 0 & \\
\hline
\end{tabular}

Table 5: Functional outcome at the end of 12 months after hemiarthroplasty among the two groups

\begin{tabular}{|c|c|c|c|c|}
\hline \multicolumn{2}{|c|}{ Functional outcome } & Cemented group $(n=30)$ & Un-cemented group $(n=30)$ & P value \\
\hline \multirow{2}{*}{ Pain } & Absent & $25(83.3 \%)$ & $19(63.3 \%)$ & \multirow{2}{*}{0.016} \\
\hline & Mild & $5(16.6 \%)$ & $11(36.6 \%)$ & \\
\hline \multirow{3}{*}{ Limp } & None & $3(10 \%)$ & $2(6.6 \%)$ & \multirow{3}{*}{0.529} \\
\hline & Mild & $26(86.6 \%)$ & $28(93.3 \%)$ & \\
\hline & Moderate & $1(3.3 \%)$ & 0 & \\
\hline \multirow{3}{*}{ Use of cane } & None & $8(26.6 \%)$ & 0 & \multirow{3}{*}{0.0318} \\
\hline & For long walks & $16(53.3 \%)$ & $22(73.3 \%)$ & \\
\hline & Most of the time & $6(20 \%)$ & $8(26.6 \%)$ & \\
\hline \multirow{6}{*}{ Range of movement } & Flexion $<60^{0}$ & $2(6.6 \%)$ & $4(13.3 \%)$ & \multirow{2}{*}{0.0816} \\
\hline & Flexion $>60^{0}$ & $28(93.3 \%)$ & $26(86.6 \%)$ & \\
\hline & Abduction $<20^{0}$ & 0 & $2(6.6 \%)$ & \multirow{2}{*}{0.619} \\
\hline & Abduction $>20^{0}$ & $30(100 \%)$ & $28(93.3 \%)$ & \\
\hline & Rotation<150 & $2(6.6 \%)$ & $2(6.6 \%)$ & \multirow{2}{*}{1.000} \\
\hline & Rotation $>15^{0}$ & $28(93.3 \%)$ & $28(93.3 \%)$ & \\
\hline
\end{tabular}

Table 6: Comparison of Harris hip score between cemented and un-cemented hemiarthroplasty groups.

\begin{tabular}{|c|c|c|c|c|c|c|}
\hline \multirow{2}{*}{ Harris hip score } & \multicolumn{2}{|c|}{ Follow-up at 3 months } & \multirow{2}{*}{$P$ value } & \multicolumn{2}{|c|}{ Follow-up at 12 months } & \multirow{2}{*}{$P$ value } \\
\hline & Cemented group & Un-cemented group & & Cemented group & Un-cemented group & \\
\hline $90-100$ (excellent) & 0 & 0 & \multirow{5}{*}{0.684} & 1 & 0 & \multirow{5}{*}{0.581} \\
\hline $80-89$ (good) & 1 & 0 & & 18 & 16 & \\
\hline $70-79$ (fair) & 29 & 28 & & 11 & 14 & \\
\hline$<70$ (poor) & 0 & 2 & & 0 & 0 & \\
\hline Mean score & $71.4 \pm 4.2$ & $70.2 \pm 3.8$ & & $81.6 \pm 4.8$ & $79.07 \pm 5.1$ & \\
\hline
\end{tabular}

$P<.001$ for comparing the scores of both the cemented and un-cemented group between the $3^{\text {rd }}$ and $12^{\text {th }}$ month of follow-up. 


\section{Conclusion}

Hemiarthroplasty, as an effective treatment, can help resume the walking ability as soon as possible, thereby reduce the risk of respiratory infection and urinary tract infection. However, there has been controversy regarding the use of cement for a long time. Our study had proven that the duration of surgery and intraoperative blood loss were less in the uncemented group as compared to cemented hemiarthroplasty group. Among the function outcome only pain reduction and use of cane was facvourable towards cemented group whereas the range of movements and limp was almost similar in both the groups and more so the Harris hip score also did not show a statistical significant difference between the two groups. So both the cemented and uncemented hemiarthroplasty are equally good options in the treatment of fracture neck of femur among elderly patients with minimal complications among the two methods. More data comparing uncemented and cemented hemiarthroplasty in patients with femoral neck fracture are still needed to substantiate our findings.

\section{References}

1. Nurmi I, Lüthje P, Narinen A, Tanninen S. Treatment outcome and overall costs of femoral neck fractures. Duodecim. 2003; 119(2):123.

2. Lönnroos E, Kautiainen H, Sund R, Karppi P, Hartikainen S, Kiviranta I et al. Utilization of inpatient care before and after hip fracture: a population-based study. Osteoporosis Int. 2009; 20(6):879-886.

3. Grübl A, Chiari C, Gruber M, Kaider A, Gottsauner-Wolf F. Cementless total hip arthroplasty with a tapered rectangular stem and a threated cup: a minimum ten-year follow-up. J Bone Joint Surg-A. 2002; 84-A:425-31.

4. Lu-Yao GL, Keller RB, Littenberg B, Wennberg JE. Outcomes after displaced fractures of the femoral neck:A meta-analysis of one hundred and six published reports. J Bone Joint Surg Am. 1994; 76:15-25.

5. Donaldson AJ, Thomson HE, Harper NJ, Kenny NW. Bone cement implantation syndrome. Br J Anaesth. 2009; 102(1):12.

6. Clark DI, Ahmed AB, Baxendale BR, Moran CG. Cardiac output during hemiarthroplasty of the hip. A prospective, controlled trial of cemented and uncemented prostheses. Journal of Bone and Joint Surgery Br. 2001; 83(3):414-8.

7. Khan RJ, MacDowell A, Crossman P, Datta A, Jallali N, Arch BN et al. Cemented or uncemented hemiarthroplasty for displaced intracapsular femoral neck fractures. Int Orthop. 2002; 26:229-232. doi: 10.1007/s00264-002-0356-2.

8. Parker MJ, Gurusamy K. Arthroplasties (with and without bone cement) for proximal femoral fractures in adults. Cochrane Database Syst Rev. 2006; 3:CD001706.

9. Figved W, Opland V, Frihagen F, Jervidalo T, Madsen JE et al. Cemented versus uncemented hemiarthroplasty for displaced femoral neck fractures. Clin Orthop Relat Res 2009; 467:2426-2435.

10. DeAngelis JP, Ademi A, Staff I, Lewis CG. Cemented versus uncemented hemiarthroplasty for displaced femoral neck fractures: a prospective randomized trial with early follow-up. J Orthop Trauma. 2012; 26:135140.

11. Taylor F, Wright M, Zhu M. Hemiarthroplasty of the hip with and without cement: a randomized clinical trial. J Bone Joint Surg Am. 2012; 94:577-583.

12. Tao Li, Qianyu Zhuang, Xisheng Weng, Lei Zhou,
Yanyan Bian. Cemented versus Uncemented Hemiarthroplasty for Femoral Neck Fractures in Elderly Patients: A Meta- Analysis. Plos One. 2013; 8(7):e68903.

13. Santini S. Hip fractures in elderly patients treated with bipolar hemiarthroplasty: comparison between cemented and cementless implants Journal of Orthopaedics and Traumatology. 2005; 6(2):80-87.

14. Bezwada HP, Shah AR, Harding SH, Baker J, Johanson NA, Mont MA. Cementless bipolar hemiarthroplasty for displaced femoral neck fractures in the elderly. J Arthroplasty. 2004; 19(7-2):73-77.

15. Bhandari M, Devereaux PJ, Tornetta P, 3rd, Swiontkowski MF, Berry DJ, Haidukewych G et al. Operative management of displaced femoral neck fractures in elderly patients: an international survey. J Bone Joint Surg Am. 2005; 87:2122-2130. doi: 10.2106/JBJS.E.00535.

16. Blomfeldt R, Tornkvist H, Eriksson K, Soderqvist A, Ponzer S, Tidermark J. A randomised controlled trial comparing bipolar hemiarthroplasty with total hip replacement for displaced intracapsular fractures of the femoral neck in elderly patients. J Bone Joint Surg Br. 2007; 89:160-165. doi: 10.1302/0301-620X.89B2.18576

17. Bhandari M, Devereaux PJ, Tornetta P et al. Operative management of displaced femoral neck fractures in elderly patients - an international survey. J Bone Joint Surg (Am). 2005; 87:2122-30.

18. Costa M, Griffin X, Pendleton N, Pearson M, Parsons N. Does cementing the femoral component increase the risk of peri-operative mortality for patients having replacement surgery for a fracture of the neck of femur? J Bone Joint Surg (Br). 2011; 93:1405-10.

19. Ahn J, Man LX, Park SD, Sodl JF. Systematic Review of Cemented and Uncemented Hemiarthroplasty Outcomes for Femoral Neck Fractures, Clin Orthop Relat Res. 2008; 466:2513-2518.

20. Ankush Mohabey V, Prajakta Warjukar R, Ravikumar M. Functional outcome of cemented versus uncemented modular bipolar hemiarthroplasty in proximal femoral neck fractures. International Journal of Orthopaedics Sciences. 2017; 3(4):609-611.

21. Parker MJ, Pryor G, Gurusamy K. Cemented versus uncemented hemiarthroplasty for intracapsular hip fractures: A randomised controlled trial in 400 patients. J Bone Joint Surg Br. 2010; 92(1):116-122.

22. Hansen SK, Brix M, Birkelund L, Troelsen A. Can introduction of an uncemented, hydroxyapatite coated hemiarthroplasty for displaced femoral neck fractures be recommended? Hip International. 2010; 20(1):109-114. 